\title{
Thermal Stress Failure of Porcelain Bonded \\ to a Palladium-Silver Alloy
}

T. R. WALTON ${ }^{1}$ and W. J. O'BRIEN

University of Michigan, School of Dentistry, Ann Arbor, Michigan 48109

Cracking or rupturing, due to thermal stress, of porcelain bonded to a palladium-silver alloy indicated that porcelain-metal thermal com. patibility was dependent on: the difference in thermal expansion coefficients of the porcelain and metal; the geometry and dimensions of the samples; and the porcelain-metal thickness ratio. A spherical configuration was more sensitive to thermal expansion coefficient differences than was a disc configuration. A higher incidence of cracking resulted from an increase in both specimen size and porcelain-metal thickness ratio.

\section{J Dent Res 64(3):476-480, March, 1985}

\section{Introduction.}

Recent research emphasis has shifted from measuring porcelain-metal bond strengths to porcelain-metal thermal compatibility. A difference in thermal expansion coefficients of the porcelain and metal has been recognized as a major parameter in predicting compatibility. The general consensus is that the alloy should have a higher thermal expansion coefficient than the porcelain (a positive expansion coefficient mismatch) in order to produce compressive stresses in the porcelain on cooling. Anusavice et al. (1980) have deduced, by means of finite element stress analysis, that residual tensile stresses will be produced with a negative expansion coefficient mismatch.

Fairhurst et al. (1981) have proposed a compatibility index for different combinations of materials from dilatometric expansion data. Bertolotti and co-workers (1979, 1980) claimed that cooling rates, viscosity through the annealing range, and metal creep would also contribute to thermal stress development. Cascone (1979) maintained that thermal conductivity of the materials was another contributing factor, while Bertolotti (1980) and Rekhson (1979) discussed the importance of the porcelain-metal thickness ratio.

The purpose of this study was to examine crack development due to thermal stress in porcelain bonded to a palladium-silver alloy and relate this to the magnitude of the differences in thermal expansion coefficients of the materials.

\section{Materials and methods.}

A palladium-silver alloy* commercially available for porcelain-metal bonding procedures was used throughout this study. A pre-cast cylindrical bar of the palladium-silver alloy was obtained from the manufacturer. We used various combinations of a high-expansion porcelain $\S$ commercially

Received for publication May 26, 1982

Accepted for publication January 4, 1985

Based on a thesis submitted in partial fulfillment of the requirements of the M.S. degree in restorative dentistry at the Horace $\mathrm{H}$. Rackham School of Graduate Studies, Ann Arbor, MI

This research was supported in part by Grant DE-05423 from NIDR, Bethesda, MD 20205.

${ }^{1}$ Current address: Unit 1, The Vintage, 281-287 Sussex Street, Sydney, N.S.W., Australia 2000

*Will Ceram, W, Williams Gold Refining Co., Inc., Buffalo, NY

$\S$ Excelco Gingival White Porcelain, Batch No. 387, Excelco Int., Santurce, Puerto Rico available for metal bonding procedures and a low-expansion porcelain recommended for use in jacket crown construction.

Thermal expansion coefficients quoted in this study were measured with a single-push rod thermal dilatometer ${ }^{\bullet}$ A cyclical heat cycle with a $4^{\circ} \mathrm{C} / \mathrm{min}$ heat rise and upper limit of $575^{\circ} \mathrm{C}$ was used. The dilatometer was calibrated with alumina and gold specimens that had known thermal expansion coefficients. A thermal expansion coefficient between 25 and $400^{\circ} \mathrm{C}$ was obtained by averaging two thermal expansion displacements for each specimen.

Rectangular porcelain test bars were fabricated by drypacking porcelain powder under $55.6 \mathrm{MPa}$ (8000 p.s.i.) pressure in a pre-fabricated mold using a hydraulic press ${ }^{\#}$. The bars were fired on platinum foil in a pre-calibrated furnace**. Three firings were used to simulate clinical conditions - twice under vacuum and once in air. A temperature cycle from 650 to $970^{\circ} \mathrm{C}$ and heat rise of $38^{\circ} \mathrm{C} /$ min were used. The bars were trimmed after the second firing so that they measured approximately $5.1 \mathrm{~cm}$ in length. These procedures ensured well-condensed, uniform, and straight bars. Gain and correction factor adjustments on the dilatometer compensated for small variations in specimen length.

Several combinations of the two commercial porcelains were prepared and mixed thoroughly in a lapidary tumbler $\S \S$ for a minimum of $12 \mathrm{hr}$. The commercial highexpansion porcelain was further modified by combination with various percentages of a leucite mineral. The mineral was ground and passed through a $75-\mu \mathrm{m}$ sieve in an ultrasonic sifter $\|$ before being mixed with the porcelain.

The palladium-silver alloy was cast into 40 discs approximately $1.8 \mathrm{~cm}$ in diameter and $1.5 \mathrm{~mm}$ thick. The discs were metallurgically polished with 240 -grit silicon carbide papers ${ }^{\bullet}$ so that they were flat and $1.3 \mathrm{~mm}$ thick. They were then air-blasted with $50 \mu \mathrm{m}$ aluminum oxide powder and degassed according to the manufacturer's recommendations.

Each of 13 test porcelains (Table 1) was applied to a minimum of two discs. The porcelain was mixed with distilled water and vibrated onto the discs using an acrylic template so that average porcelain thickness after firing was $1.5 \mathrm{~mm}$. As with the rectangular bar specimens, the discshaped porcelain-metal specimens were fired under vacuum from 650 to $970^{\circ} \mathrm{C}$ with a heat rise of $38^{\circ} \mathrm{C} / \mathrm{min}$. They were then allowed to bench-cool.

ISteeles Vacuum Aluminous Porcelain E69, Columbus Dental $\mathrm{Mfg}$. Co., Columbus, $\mathrm{OH}$

Harrop Laboratories, Division of Harrop Ceramic (Serv. 6), Columbus, $\mathrm{OH}$

\#Dake Hydrolic Press, Dake Corporation, Grand Haven, MI

**Ney Mark III, J.M. Ney Company, Bloomfield, CT

$\S \S$ Loitone Compact Lapidary Tumbler, The Carborundum Co., Seattle, WA

I Allen Bradley Sonic Sifter, Distr. by Fisher Scientific Co., Pittsburgh, PA

$\bullet$ Wetordry Tri-M-ite Paper Discs, 3M Manufacturing Company, St. Paul, MN 
The compound discs were visually examined after $24 \mathrm{hr}$ and the development of cracks noted. The porcelain was then ground to $0.75 \mathrm{~mm}$ thickness. The discs were re-fired, cooled, and re-examined after a further $24 \mathrm{hr}$. The acrylic template was next modified so that fired porcelain thickness was approximately $2.5 \mathrm{~mm}$. The test porcelains were then added to their respective discs, fired, cooled, and examined as previously described.

The palladium-silver alloy was also cast into 40 spheres $7.8 \mathrm{~mm}$ in diameter, with sprued plastic balls as patternformers. Approximately $0.5 \mathrm{~cm}$ length of sprue was left attached to the spheres for ease of handling. The spheres were air-blasted with $50 \mu \mathrm{m}$ aluminum oxide powder and degassed according to the manufacturer's recommendations.

Weighed amounts of $1.5 \mathrm{~g}$ of each of the 13 test porcelains were applied to a minimum of two spheres, condensed, dried, fired, and examined as described for the discs. The porcelain thickness after firing was approximately $1.5 \mathrm{~mm}$. The specimens were examined again after six wk.

Compound spheres were similarly prepared using five different weighed amounts of the commercial high-expansion porcelain bonded to each of two sphere sizes $(7.8 \mathrm{~mm}$ and $9.2 \mathrm{~mm}$ in diameter).

\section{Results.}

The thermal expansion coefficients measured between 25 and $400^{\circ} \mathrm{C}$ for the palladium-silver alloy, the high-expansion porcelain, and the low-expansion porcelain were $14.4 \mathrm{x}$ $10^{-6} /{ }^{\circ} \mathrm{C}, 13.6 \times 10^{-6} /{ }^{\circ} \mathrm{C}$, and $6.9 \times 10^{-6} /{ }^{\circ} \mathrm{C}$, respectively. The metal exhibited linear thermal expansion between 25 and $575^{\circ} \mathrm{C}$, while many of the porcelains showed a deviation from linear expansion in the interval between 400 and $575^{\circ} \mathrm{C}$. Observed deviation was enhanced with increased leucite content.

Fig. 1 shows graphically the effect on thermal expansion obtained by addition of the low-expansion porcelain to the high-expansion porcelain. An average fall of $0.75 \%$ in coefficient values resulted with every $1 \%$ addition of the lowexpansion porcelain.

Fig. 2 shows graphically the effect on thermal expansion obtained by addition of the leucite mineral to the highexpansion porcelain. An average rise of $0.5 \%$ in coefficient values resulted with every $1 \%$ addition of the leucite mineral.

Table 1 shows the composition and thermal expansion coefficients of the selected test porcelains. Coefficient values ranged from 9.3 to $16.8 \times 10^{-6} \%^{\circ} \mathrm{C}$.

Table 2 compares the incidence of cracking obtained for the compound disc and sphere specimens having a fired porcelain thickness of approximately $1.5 \mathrm{~mm}$. All compound discs with porcelains having thermal expansion coefficients of or below $10.6 \times 10^{-6} /{ }^{\circ} \mathrm{C}$ cracked within 24 hr. All compound sphere specimens with porcelains having thermal expansion coefficients of or below $12.6 \times 10^{-6} /{ }^{\circ} \mathrm{C}$ cracked or ruptured within $24 \mathrm{hr}$. Note the small difference in coefficient values $\left(13.4\right.$ as against $12.6 \times 10^{-6} /{ }^{\circ} \mathrm{C}$ between cracked and stable spherical specimens). Note also that only one of five specimens containing porcelain with a thermal expansion coefficient of $13.0 \times 10^{-6}$ remained intact. A cohesive failure of the porcelain was observed for all ruptured specimens, and a minimum of $0.2 \mathrm{~mm}$ of porcelain remained bonded to the metal.

Figs. 3 and 4 show examples of a cracked disc and

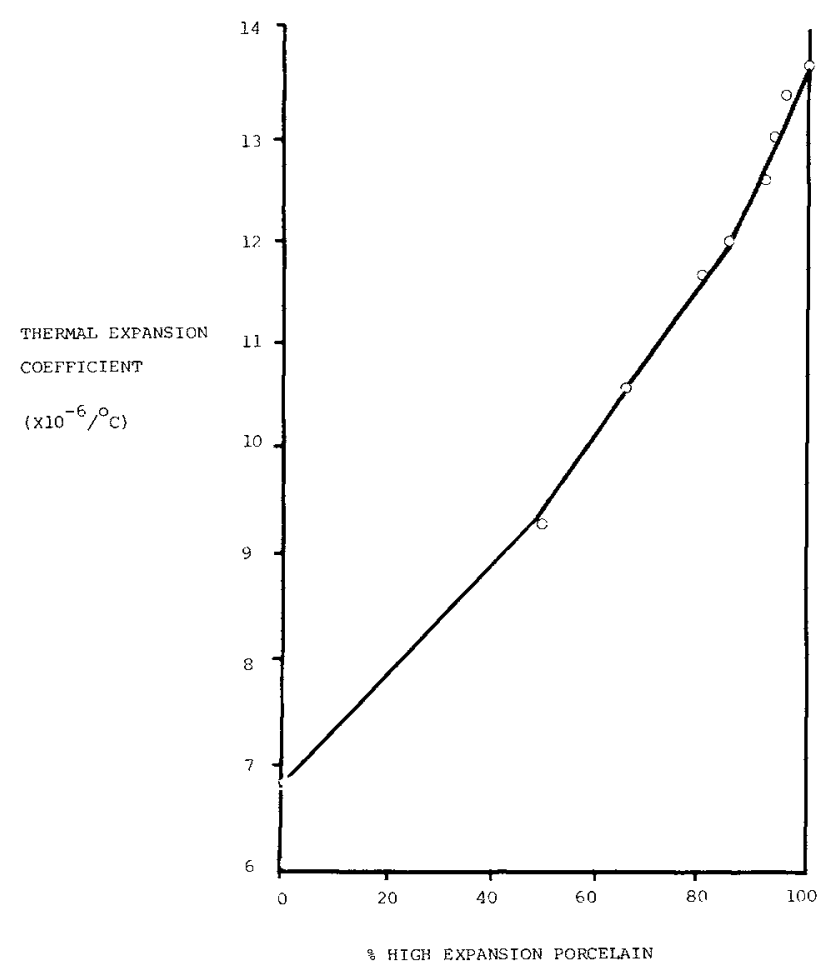

Fig. 1 - Thermal expansion coefficients of porcelains obtained by mixture of the high-and low-expansion porcelains.

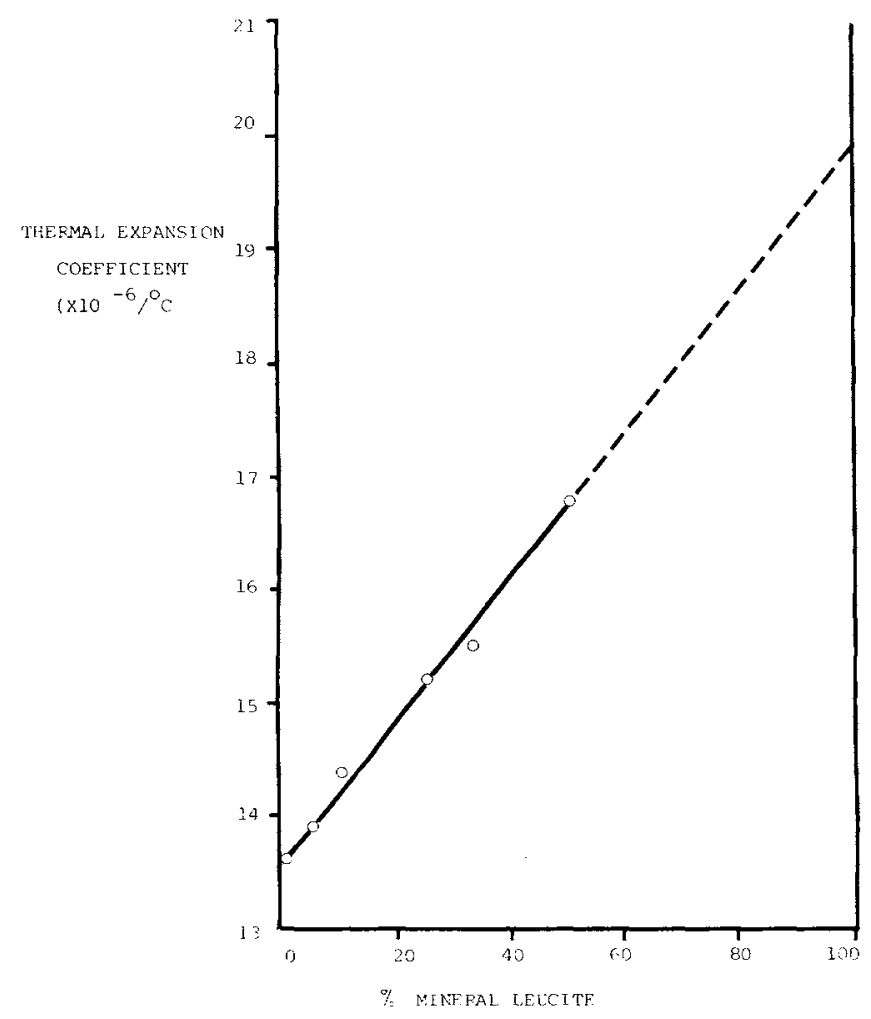

Fig. 2 - Thermal expansion coefficients of porcelains obtained by addition of leucite mineral to the high-expansion porcelain. 
TABLE 1

COMPOSITION AND THERMAL EXPANSION COEFFICIENTS OF THE TEST PORCELAINS

\begin{tabular}{rcccc}
\hline \hline & \multicolumn{3}{c}{ \% Composition } & Thermal Expansion \\
\cline { 2 - 4 } ID. & $\begin{array}{c}\text { High-expansion } \\
\text { No. }\end{array}$ & $\begin{array}{c}\text { Low-expansion } \\
\text { Porcelain }\end{array}$ & $\begin{array}{c}\text { Leucite } \\
\text { Porcelain }\end{array}$ & $\begin{array}{c}\text { Mineral } \\
\left(\mathrm{X} 10^{-6}{ }^{-6} \mathrm{C}\right)\end{array}$ \\
\hline 1 & 50 & 0 & 50 & 16.8 \\
2 & 66.6 & 0 & 33.3 & 15.5 \\
3 & 75 & 0 & 25 & 15.2 \\
4 & 90 & 0 & 10 & 14.4 \\
5 & 95 & 0 & 5 & 13.9 \\
6 & 100 & 0 & 0 & 13.6 \\
7 & 96 & 4 & 0 & 13.4 \\
8 & 94 & 6 & 0 & 13.0 \\
9 & 92 & 8 & 0 & 12.6 \\
10 & 85 & 15 & 0 & 12.0 \\
11 & 80 & 20 & 0 & 11.7 \\
12 & 66.6 & 33.3 & 0 & 10.6 \\
13 & 50 & 50 & 0 & 9.3 \\
\hline
\end{tabular}

TABLE 2

CRACK DEVELOPMENT IN COMPOUND DISC AND COMPOUND SPHERE SPECIMENS AFTER 24 HOURS

\begin{tabular}{cccc}
\hline \hline & $\begin{array}{c}\text { Thermal Exp. } \\
\text { Test } \\
\text { Coefficient } \\
\left(\mathrm{X} 10^{-6} /{ }^{\circ} \mathrm{C}\right)\end{array}$ & & \multicolumn{2}{c}{$\begin{array}{c}\text { Incidence of Cracking } \\
\text { Number Cracked/Sample Size }\end{array}$} \\
\cline { 4 - 4 } $1-6$ & $16.8-13.6$ & & no cracking in any specimen \\
7 & 13.4 & $0 / 2$ & $0 / 5$ \\
8 & 13.0 & $0 / 2$ & $4 / 5$ \\
9 & 12.6 & $0 / 2$ & $5 / 5$ \\
10 & 12.0 & $0 / 2$ & $2 / 2$ \\
11 & 11.7 & $0 / 5$ & $2 / 2$ \\
12 & 10.6 & $5 / 5$ & $2 / 2$ \\
13 & 9.3 & $5 / 5$ & $2 / 2$ \\
& & &
\end{tabular}

spherical specimen, respectively. Fig. 5 shows ruptured spherical specimens.

Fig. 6 compares these results and relates them to the expansion of the metal. Although the porcelain thickness was approximately the same for all specimens, the porcelainmetal thickness ratio was $1: 1$ and $1: 2$ for disc and sphere specimens, respectively. As can be seen in Fig. 7, when the thickness ratio of the disc was reduced to $1: 2$ (the same ratio as for the spherical specimens), no specimens cracked. Thus, porcelains with expansion coefficients as low as $9.3 \mathrm{x}$ $10^{-6} /{ }^{8} \mathrm{C}$ were stable. When the thickness ratio of the discs was increased to $2: 1$, disc specimens with porcelains having thermal expansion coefficient values of $11.7 \times 10^{-6} /{ }^{\circ} \mathrm{C}$ or lower cracked within $24 \mathrm{hr}$.

Fig. 8 compares the incidence of cracking obtained when the commercial porcelain (ID. No. 6) was applied to the two sphere sizes with different porcelain-metal thickness ratios. Metal spheres $7.8 \mathrm{~mm}$ in diameter were not stable when the thickness ratio was $1: 1$ but were stable when the thickness ratio was $1: 2$ or less. A $1: 2$ thickness ratio, however, was not stable when the larger metal sphere, $9.2 \mathrm{~mm}$ in diameter, was used. Only a ratio of 1:4 was stable for the larger sphere. These observations are summarized in Table 3.

\section{Discussion.}

The single-push rod thermal dilatometer proved consistent and reliable for measuring the thermal expansion coefficients of both the metal alloy and porcelains. The

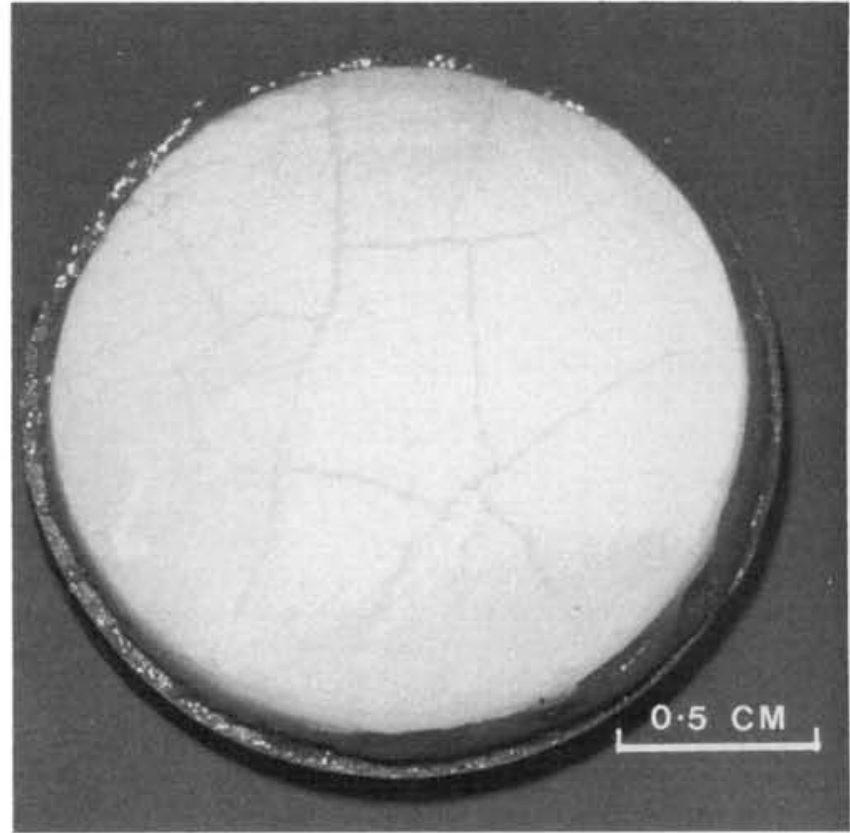

Fig. 3 - A compound disc exhibiting cracking of the porcelain.

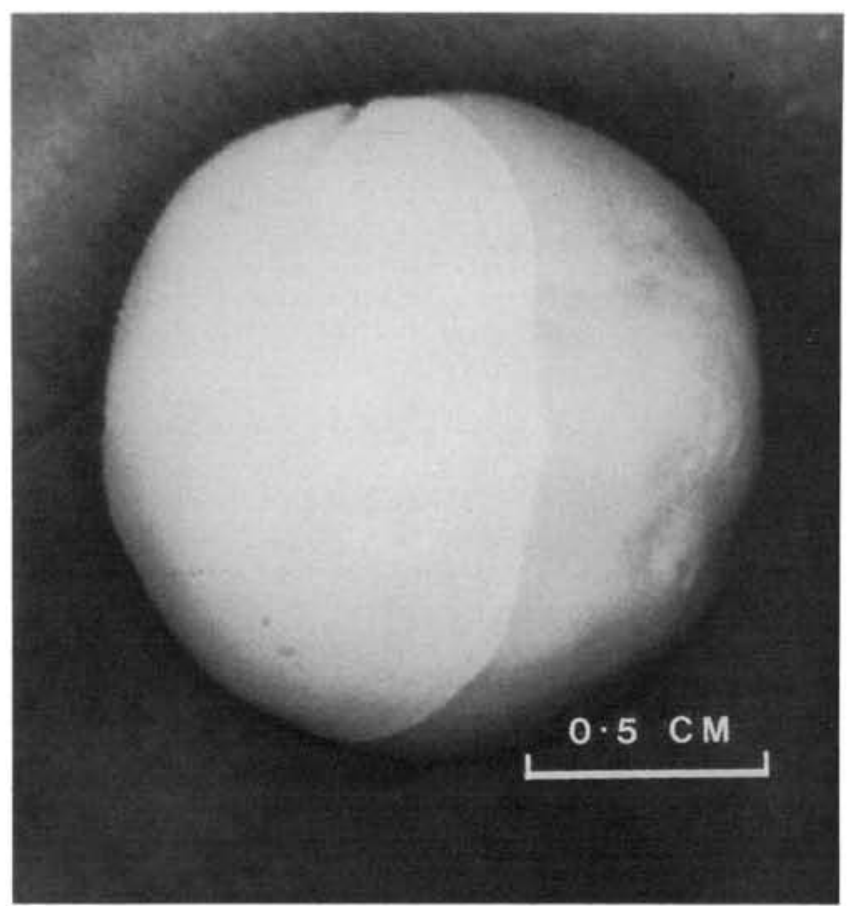

Fig. 4 - A compound sphere exhibiting cracking of the porcelain.

thermal expansion of porcelains was modified by alteration of the glass or crystal phases. The measured dilatometric values for coefficient of thermal expansion were very similar for the two replicate porcelain specimens of each composition.

Thermal stress failure was evidenced by checking, cracking, or rupture of the porcelain following visual examination. It must be conceded that microscopic examination may have revealed otherwise-undetected cracking. However, the same limitation would be apparent for any degree of magnification. Visual examination is used to assess the clinical acceptance of compatibility of porcelain-metal 


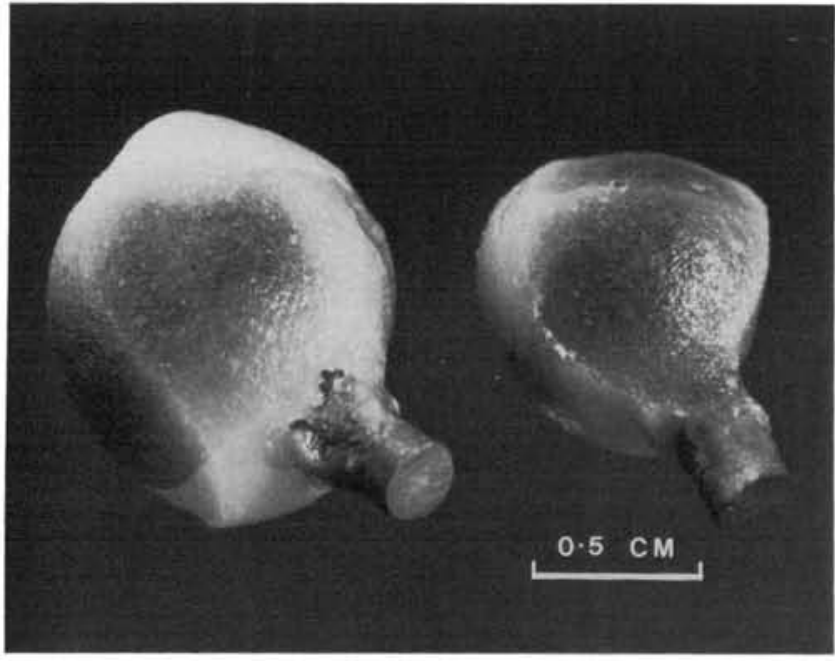

Fig. 5 - Compound spheres exhibiting rupture of the porcelain.

(PORCELAIN : METAL THICKNESS RATIO $=1: 1$ )

CRACKS

NO CRACKS

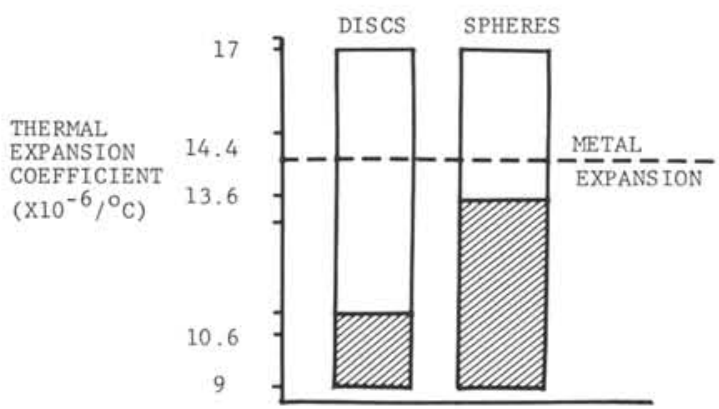

Fig. 6 - Crack development in compound structures: Influence of geometric shape.

restorations. Examination of ruptured specimens indicated that the porcelain-metal interface bond strength was greater than the strength of the porcelain.

Timoshenko (1925) proposed that thermally induced stresses in bi-material strips could be calculated using the formula $\rho \max =\mathrm{K}(\Delta \alpha \Delta \mathrm{T})$, where $\rho \max$ is the maximum tensile or shear stress, $\Delta \alpha$ is the difference in thermal expansion coefficients of the two materials, and $\Delta T$ is the temperature range through which such stress would be developed.

Neilsen and Tuccillo (1972) claimed that this stress equation could also be applied to the porcelain-metal combinations used in dentistry. They claimed that the $\mathrm{K}$ factor became a function of specimen geometry and modulus of elasticity (E), and formulated $\mathrm{K}$ values of $0.5 \mathrm{E}, 1.13 \mathrm{E}$, and 1.7E for compound discs, cylinders, and spheres, respectively. Thus, highest shear stress values would be generated in a compound sphere for any given difference in thermal expansion coefficients. They claimed that stress development was not very sensitive to an increase in porcelain relative to metal thickness.

In this study, the incidence of cracking or rupture of the porcelain due to thermal stress was significantly affected by

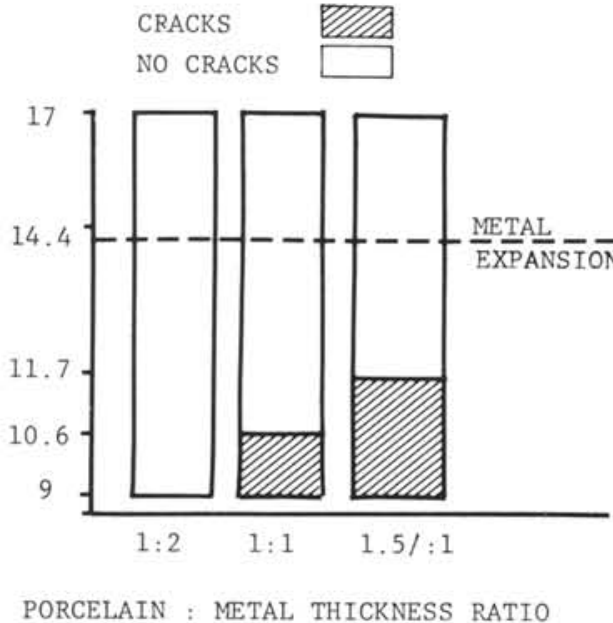

Fig. 7 - Crack development in compound discs: Influence of porcelain:metal thickness ratio.

( THERMAL EXPANSION COEFFICIENT $=13.6 \times 10^{-6} /{ }^{\circ} \mathrm{C}$ )
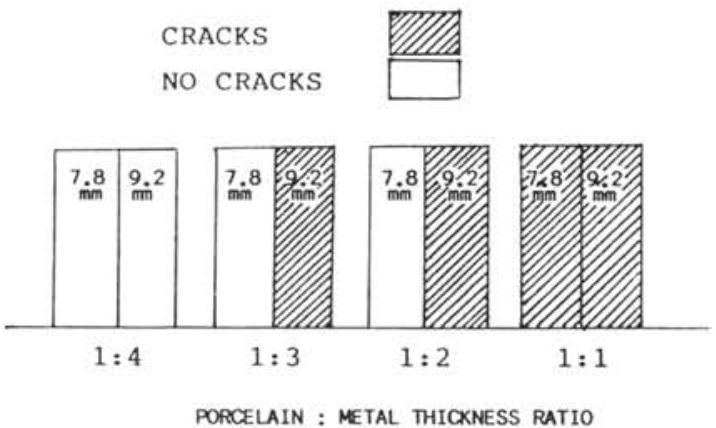

Fig. 8 - Crack development in compound spheres: Influence of dimension of specimen.

thermal expansion differences of the metal and porcelain and by the geometry of the compound structures.

Thermal expansion mismatches of $28 \%$ and $10 \%$ resulted in thermal stress failure of the compound disc and compound sphere specimens, respectively, provided that the thickness ratio was unity. The results thus confirm stress calculations which predict high thermal stresses for both small differences in thermal expansion of the materials and a spherical specimen design.

The results also indicated that the porcelain-metal thickness ratio and dimensions of the compound structures significantly affected the incidence of cracking. Differential cooling rates of the materials, or thermal gradients through them, may be affected by these factors. Grinding the porcelain to $0.75 \mathrm{~mm}$ thickness and then re-firing it did not appear to cause additional subsequent fracture of the test specimens.

Shell and Nielsen (1962) postulated that, for thin porcelain deposits, the residual thermal stress decreased proportionally to the distance from the porcelain-metal interface, reaching near-zero stress at the porcelain surface. For thick porcelain layers, they predicted that a compressive stress at the interface decreased to zero within the porcelain and then changed to a tensile stress which increased with the thickness of the porcelain. Examination of ruptured spherical specimens obtained in this study indicated that the 
TABLE 3

CRACK DEVELOPMENT IN SPECIMENS CONTAINING TEST PORCELAIN NUMBER 6 APPLIED TO TWO SPHERE SIZES

\begin{tabular}{ccc}
\hline & \multicolumn{2}{c}{$\begin{array}{c}\text { Incidence of Cracking } \\
\text { Number Cracked/Sample Size }\end{array}$} \\
\cline { 2 - 3 } Porcelain:Metal & $7.8 \mathrm{~mm}$ & $9.2 \mathrm{~mm}$ \\
\hline $1: 4$ & $0 / 2$ & $0 / 5$ \\
$1: 3$ & $0 / 2$ & $5 / 5$ \\
$1: 2$ & $0 / 5$ & $2 / 2$ \\
$1: 1$ & $5 / 5$ & $2 / 2$ \\
\hline
\end{tabular}

maximum stress within the porcelain occurred at a distance of approximately $0.2 \mathrm{~mm}$ from the porcelain-metal interface.

None of the negative thermal expansion mismatches resulted in cracking in either the disc or sphere specimens. These results contradict theoretical calculations which predict higher thermal stresses when the expansion of the porcelain exceeds that of the metal.

It should be emphasized, however, that the dilatometric thermal expansion data were obtained with a controlled heating rate of $4^{\circ} \mathrm{C} / \mathrm{min}$. Thermal stress development in the compound porcelain-metal specimens occurs during the cooling cycle, where temperature change is approximately two orders of magnitude greater than the controlled heating rate of the dilatometric cycles. Actual thermal expansion/ contraction coefficient differentials in the compound specimens may have differed significantly from dilatometric thermal expansion data. Bertolotti and Fukui (1982) have shown a change in the porcelain-softening range as the compositions of porcelains varied. Mixtures of the highand low-expansion porcelains in this study could have resulted in differences in the porcelain-softening temperatures of the resultant test porcelains, thus affecting the integrated differential length of the materials in the compound specimens during the bench-cooling cycle. This further limits the value of correlations between dilatometric thermal expansion data and cracking of the compound specimens.

The observation that some compound spheres developed cracks after six wk, although stable after $24 \mathrm{hr}$, indicated that a reduction in developed thermal stress did not occur with time. Environmental and residual thermal stress effects may have contributed to crack propagation and growth.

The results obtained in this study apply only to the porcelains and metal alloy tested. No correlation with other porcelain and alloy combinations is to be assumed. Furthermore, the thermal expansion mismatches quoted apply to the expansion coefficients in the specified temperature range. A linear expansion behavior of these and other commercial porcelains is not assumed.

\section{Acknowledgment.}

The authors would like to thank the Williams Gold Refining Company and the Excelco Company for providing the metal and porcelain used in this study.

\section{REFERENCES}

ANUSAVICE, K.J.; DeHOFF, P.H.; and FAIRHURST, C.W. (1980): Comparative Evaluation of Ceramic-Metal Bond Tests Using Finite Element Stress Analysis, J Dent Res 59:603-613.

BERTOLOTTI, R.L. (1980): Calculation of Interfacial Stress on Porcelain-Fused-to-Metal Systems, J Dent Res 59:1972-1977.

BERTOLOTTI, R.L. and FUKUI, H. (1982): Measurement of Softening Temperatures in Dental Bake-on Porcelains, $J$ Dent Res 61:480-483.

BERTOLOTTI, R.L. and MOFFA, J.P. (1980): Creep Rate of Porcelain Bonding Alloys as a Function of Temperature, $J$ Dent Res 59:2062-2070.

BERTOLOTTI, R.L. and SHELBY, J.E. (1979): Viscosity of Dental Porcelain as a Function of Temperature, $J$ Dent Res 58:20012006.

CASCONE, P.J. (1979): Effect of Thermal Properties on Porcelainto-Metal Compatibility, IADR Progr \& Abst 58:No. 683

FAIRHURST, C.W.; ANUSAVICE, K.J.; RINGLE, R.D.; and TWIGGS, S.W. (1981): Porcelain Metal Thermal Compatibility, $J$ Dent Res 60:815-819.

NIELSEN, J.P. and TUCCILLO, J.I. (1972): Calculation of Interfacial Stress in Dental Porcelain Bonded to Gold Alloy Substrate, $J$ Dent Res 51:1043-1047.

REKHSON, S.M. (1979): Annealing of Glass-to-Metal and Glass-toCeramic Seals, Part 1. Theory, Glass Technology 20:27-35.

SHELL, J.S. and NIELSEN, J.P. (1962): Study of the Bond Between Gold Alloys and Porcelain, $J$ Dent Res 41:1424-1437.

TIMOSHENKO, S. (1925): Analysis of Bi-Metal Thermostats, JOpt Soc Am 11:233-255. 